\title{
Progression to Complete Heart Block in a Patient With Myotonic Dystrophy
}

\author{
Anthony Weber ${ }^{\mathrm{a}, \mathrm{b}}$, Joseph Elliotta ${ }^{\mathrm{a}}$, Kevin Frey $^{\mathrm{a}}$
}

\begin{abstract}
Myotonic dystrophy type 1 is the most common inherited neuromuscular disorder and is associated with a high incidence of sudden cardiac death. Early recognition and prophylactic primary prevention for cardiac conduction defects has been shown to increase survival of these patients. Increasing awareness among physicians could result in survival benefit close to a decade for this population of patients.
\end{abstract}

Keywords: Myotonic dystrophy; Cardiac conduction abnormalities; Complete heart block; Primary prevention

\section{Introduction}

Myotonic dystrophy type 1 is a multisystem disorder not only affecting skeletal muscle but often involving the myocardium. It is the most common muscular disorder associated with reported sudden cardiac death [1]. Mortality rate is 7.3 times greater than the general population with the mean age of death at 53 years [2]. Unfortunately, there is no correlation between severity of disease and the amount of cardiac involvement [3]. Cardiac conduction delays and blocks are also a common manifestation of this disease, in up to $90 \%$ of patients, potentially leading to lethal arrhythmias [4]. This case report exams this progressive process and aims to expand on early recognition, timing and prevention of these complications.

\section{Learning objectives}

1) Raise awareness for cardiac screening in patient with myotonic dystrophy for primary care providers, cardiologist, and neurologist.

2) Consider primary prevention in patients with myotonic

Manuscript submitted February 24, 2018, accepted March 15, 2018

${ }^{a}$ Canton Medical Education Foundation at Aultman Hospital, 2600 Sixth St SW, Canton, OH 44710, USA

${ }^{b}$ Corresponding Author: Anthony Weber, Canton Medical Education Foundation at Aultman Hospital, 2600 Sixth St SW, Canton, OH 44710, USA.

Email: Anthony.Weber@aultman.com

doi: https://doi.org/10.14740/jmc3028w dystrophy and conduction abnormalities.

3) Treatment of severe conduction abnormalities in myotonic dystrophy.

4) Demonstrate the range of electrocardiogram abnormalities in myotonic dystrophy.

5) Recognize signs and symptoms of myotonic dystrophy.

\section{Case Report}

A 58-year-old Caucasian male with significant past medical history of myotonic dystrophy and no significant cardiac history presented to emergency department with intermittent atypical chest pain while endorsing associated palpitations, weakness, and fatigue for 2 weeks. Previous medical records confirmed a diagnosis of Mobitz type I second degree AV block on EKG performed the previous week. During his admission, cardiac enzymes including troponin I and proBNP were within normal limits. Multiple episodes of sinus bradycardia were noted on telemetry with a follow-up EKG revealing first degree AV block. Over the course of $7 \mathrm{~h}$, the patient became symptomatic with dizziness and altered mental status, while his vital signs showed a heart rate of 32 and blood pressure of 64/32. Serial EKGs were performed showing a conversion into complete heart block and junctional escape rhythm. The patient was resuscitated with dopamine for hemodynamic stability. Emergent permanent pacemaker placement was performed without complication. Following an uncomplicated recovery, echocardiogram and nuclear stress testing showed no structural or identifiable ischemia.

\section{Discussion}

Myotonic dystrophy is a rare condition from a triplet expansion on chromosome $19 \mathrm{q} 13.3$ with reported incidence in around 1 in 8,000 worldwide. The chromosomal expansion mutation results in a gain of function mutation for involved cells. This gain of function is expressed as the common features associated with this rare disease. The disease is slowly progressive with physical features of increased muscle weakness and muscle atrophy commonly involving distal, smaller muscle groups. This clinical presentation can be congenital, juvenile, adult or late onset depending on the severity of the disease.

Cardiac conduction abnormalities in myotonic dystrophy range from benign first-degree heart block to malignant ven- 
tricular arrhythmias. Subsequent studies found that $20-30 \%$ of patients die of cardiac causes and $33 \%$ are sudden cardiac death. Recent data suggest that myocardial fibrosis and infiltrative adipose tissue involving the myocardium affects the electrical conduction system. The rates of EKG abnormalities are significantly higher than the general population. Multiple abnormalities include widening of the QRS complexes, abnormal Q waves, bundle branch blocks and bradycardia. Given the progressive nature of the disease and identifiable findings, regular cardiac monitoring and yearly monitoring with $\mathrm{EKG}$ is recommended.

Abrupt appearance of heart block may contribute to sudden cardiac death [5]. It has been established that sudden cardiac death may occur despite pacemaker implantation [6]. Electrophysiological studies with prophylactic pacemaker placement and ICD is recommended for those at risk for severe bradycardia, high degree AV block or malignant ventricular arrhythmia. There is a class I recommendation for device placement for the high risk patients but unfortunately prophylactic pacing is rarely pursued, even though lower mortality and increased survival rates have been shown [7-9]. Patient with high risk EKGs, defined as PR interval greater than 200 $\mathrm{ms}$ and/or QRS duration greater than $100 \mathrm{~ms}$, who underwent invasive implantation of a prophylactic pacing device showed a significant survival benefit of 9 years when compared to their non-invasive counterparts [9].

Increased awareness among general practitioners and appropriate coordination of care involving with fields of neurology and cardiologist would benefit these patients long-term survival. As of now, only symptomatic treatment is indicated for these patients, but there is growing research investigation targeting treatment on a molecular level [10].

\section{Conflict of Interest}

The authors listed above certify that they have no affiliation or involvement with any organization or entity, and also have no financial or non-financial interest in the subject matter or materials discussed in this manuscript.

\section{References}

1. Finsterer J, Stollberger C, Maeztu C. Sudden cardiac death in neuromuscular disorders. Int J Cardiol. 2016;203:508515.

2. Omond KJ, Byard RW. Forensic considerations in cases of myotonic dystrophy at autopsy. J Forensic Sci. 2017;62(6):1496-1499.

3. Florek RC, Triffon DW, Mann DE, Ringel SP, Reiter MJ. Electrocardiographic abnormalities in patients with myotonic dystrophy. West J Med. 1990;153(1):24-27.

4. Bird TD. Gene Reviews myotonic dystrophy type I. Seattle WA: University of Washington; 1999.

5. Griggs RC, Davis RJ, Anderson DC, Dove JT. Cardiac conduction in myotonic dystrophy. Am J Med. 1975;59(1):37-42.

6. Cannom DS, Wyman MG, Goldreyer BN. Clinical and induced ventricular tachycardia in a patient with myotonic dystrophy. J Am Coll Cardiol. 1984;4(3):625-628.

7. Khalighi K, Kodali A, Thapamagar SB, Walker SR. Cardiac involvement in myotonic dystrophy. J Community Hosp Intern Med Perspect. 2015;5(1):25319.

8. European Heart Rhythm A, Heart Rhythm S, Zipes DP, Camm AJ, Borggrefe M, Buxton AE, Chaitman B, et al. ACC/AHA/ESC 2006 guidelines for management of patients with ventricular arrhythmias and the prevention of sudden cardiac death: a report of the American College of Cardiology/American Heart Association Task Force and the European Society of Cardiology Committee for Practice Guidelines (Writing Committee to Develop Guidelines for Management of Patients With Ventricular Arrhythmias and the Prevention of Sudden Cardiac Death). J Am Coll Cardiol. 2006;48(5):e247-346.

9. Wahbi K, Meune C, Porcher R, Becane HM, Lazarus A, Laforet P, Stojkovic T, et al. Electrophysiological study with prophylactic pacing and survival in adults with myotonic dystrophy and conduction system disease. JAMA. 2012;307(12):1292-1301.

10. Romeo V. Myotonic Dystrophy Type 1 or Steinert's disease. Adv Exp Med Biol. 2012;724:239-257. 